IJCOM 2021 November; $1(2): 41-3$

\title{
EDITORIAL
}

\section{Indonesian Health Workers during COVID-19 Pandemic}

\author{
Ari Fahrial Syam \\ Department of Internal Medicine, Faculty of Medicine, Universitas Indonesia \\ Corresponding address: Ari Fahrial Syam \\ Emailari_syam@hotmail.com
}

I have been a doctor for 30 years, and I have gone through various life experiences throughout my long journey in this profession. However, my experience as a doctor during the global COVID-19 pandemic was the toughest compared to all my previous challenges.

My early medical career in remote areas was utterly challenging; there was always a risk of being bitten by snakes or being attacked by a wild animal. I faced multiple malaria infections when I worked, and the experience was horrifying. As an internal medicine specialist, I volunteered in the Aceh tsunami, Yogyakarta earthquake, West Sumatra earthquake, Jakarta flood, and other disasters with continuous risks of repeated earthquakes or scarcity in food supplies.

However, those experiences pale compared to the current global COVID-19 pandemic; these are the toughest days for doctors and other health workers as COVID-19 infection spreads quickly from one person to another. The pandemic also caused a broad impact on the economy and health globally. Indonesia is currently struggling to prevent the transmission and infection of the disease while the world faces unprecedented global health and socioeconomic crisis triggered by the COVID-19 pandemic.

The first COVID-19 virus was found in Indonesia on the 2nd of March 2020, and the infection rate continued to grow. Lack of personal protective equipment, limited ventilators, burnout from health workers were problems faced globally in the early days of the pandemic. At the start of this pandemic, public opinion regarding the coronavirus risk was mistakenly considered similar to the common cold or annual influenza viruses. This misunderstanding might have been induced by the similarity in the spreading patterns and some of the symptoms.

When the world faces a global pandemic, everyone seems to have the same urgent needs-the need for masks and personal protective equipment. Doctors and nurses especially rely on personal protective equipment to protect themselves and their patients from being infected and infecting others. Everyone is scrambling to look for a cure and a vaccine, which is currently faced by countries globally. The most impacted by this condition are the health workers, especially the doctors who are still providing care face to face with their patients. When providing face-toface health care during the pandemic, health care workers should take steps to keep themselves and their patients safe. World institutions such as WHO stress that health workers should be prioritised regarding access to personal protective equipment. ${ }^{1}$

The World Health Organization also mentioned severe and mounting disruption to the global supply of personal protective equipment (PPE) - caused by rising demand, panic buying, hoarding, and misuse. This problem should become a motivation to realise the "independence of the nation" jargon in terms of production and provision of PPE. We should be motivated to change the phrase from jargon to an actual way of life.

The global COVID-19 pandemic is extraordinary, particularly because of the social distancing measures. This measure means that we cannot move freely, interact directly, and hold meetings or meetings in a closed room for coordination to overcome this problem. While at the same time rapidly evolving landscape of the global COVID-19 pandemic needs urgent scientific advances, adaptive behavioural and government responses to contain the viral transmission, reduce impacts on public health, minimise societal disruption and economic loss. 
At the same time, it is hard to implement these social distancing measures in a clinical setting. Health workers can be infected directly from patients being served, both in polyclinics and in inpatient conditions. I have predicted that the current direct contact transmission model will make health workers victims of the pandemic. The Indonesian Doctors Association reported that the number of doctors who died in Indonesia was one of the highest in the world. A total of 114 doctors died from July 1 st - 17th, and it accounts for more than $20 \%$ of the 545 total COVID related death in doctors since the pandemic. ${ }^{2}$

The condition worsens due to undermining the mental health of the health workers, especially with negative accusations against them followed by the social stigma that appears in the community to health workers. One of the high cases of COVID-19 related problems in Indonesian health care workers is burnout or work fatigue. A study conducted by the Department of Community Medicine, Faculty of Medicine, University of Indonesia (FKUI) found that $83 \%$ of health workers experience moderate to severe burnout due to stressors and conflicts at work, such as emotional exhaustion and loss of empathy, and reduced self-confidence. ${ }^{3}$

Burnout in health workers causes physical and emotional fatigue; it is a condition of a long-term affective state and is an outcome of cumulative and chronic exposure to stress, particularly work stress. Burnout was especially evident in hospitals with limited availability of medical staff. Mental burdens are higher because they face more patients infected by the coronavirus, followed by the trauma of witnessing deaths among patients. These conditions may weaken the immune system, increasing vulnerability to COVID-19 and higher risk of severe symptoms that can cause death. When talking out of context of the pandemic, burnout can also be associated with various other diseases, including IBS. ${ }^{4}$ Burnout was associated with a 2.41-fold elevated prevalence of IBS after adjusting for potential confounding variables, including job strain. ${ }^{5}$

Other studies reported that health workers treating COVID-19 patients experience significantly higher depressive symptoms and burnout than others. The percentage of health care workers experiencing anxiety was also higher despite insignificant differences in the chance for it to raise. Anxiety can increase as a consequence of pandemic conditions, not just because of managing the disease. Overall this shows that health workers in contact with COVID-19 patients have a higher risk of psychological trauma from work. ${ }^{6}$

In addition to burnout, several other factors (often neglected) cause the high mortality rate in health workers; these include comorbidities, workload factors, and age (with average death occurring in 45 years old). Lack of personal protective equipment had also contributed to the death of health workers at the start of the pandemic.

The government must pay full attention to the high death rate of doctors due to COVID-19. Steps can be taken by continuing to keep the COVID-19 cases from increasing again. The difficult period at the beginning of the pandemic, which repeated during the second wave of June-July 2021, should not happen again. Because once again, its dire consequences will impact health workers the most. It took many years and effort to create one doctor, from initial education to specialist and consultant. Hopefully, Indonesia will not enter the third wave of the pandemic.

On another note, there are also ongoing efforts done by the government to improve the fate of health workers; this includes incentives (even though at the beginning, the process was a bit sluggish) and priority for COVID vaccination. Currently, most of our health workers have received the third booster vaccine. Various facilities and infrastructure were also provided so that doctors could work peacefully. Procurement of masks, personal protective equipment, and hand sanitisers continue to improve, and scarcity has been managed. The Indonesian people have finally learned that national independence is important, including producing their own personal protective equipment. In some circumstances, health workers are assisted by the advancement of high information technology. Consultations with patients can be done online to reduce face-to-face contact with patients, followed by the new telemedicine trend.

Indonesia is currently one of the countries that have succeeded in controlling the pandemic, proven by the number of new cases that had been controlled. Inpatient wards at the hospital previously used to treat COVID-19 patients have also been reverted to being a regular patient room. This condition had somewhat relaxed doctors even though they remain vigilant and strictly screen patients for medical treatment. Doctors must be consistent in maintaining health protocols and continue to use proportional personal protective equipment. This condition will provide an opportunity for doctors and health workers to work in peace. We must unite, understand each other, stay positive; we can only beat this virus together. 


\section{Reference}

1. Widjaja FF, Shatri H, Putranto R. Health Issues Among Healthcare Workers During COVID-19 Pandemic: a Psychosomatic Approach. Acta Med Indones. 2020 Apr;52(2):172-176. PMID: 32778632.

2. The Jakartapost.com. Indonesia reports record number of doctor deaths from COVID-19 in July". Avalaible from https:// www.thejakartapost.com/news/2021/07/18/indonesia-reportsrecord-number-of-doctor-deaths-from-covid-19-in-july.html.

3. Tempo.co. 83\% Health Workers in Indonesia Experiencing Pandemic Burnout, Study Finds. Available from https:// en.tempo.co/read/1422341/83-health-workers-in-indonesiaexperiencing-pandemic-burnout-study-finds

4. Quek SXZ, Loo EXL, Demutska A, Chua CE, Kew GS, Wong S, Lau HX, Low EXS, Loh TL, Lung OS, Hung ECW,
Rahman MM, Ghoshal UC, Wong SH, Cheung CKY, Syam AF, Tan N, Xiao Y, Liu JS, Lu F, Chen CL, Lee YY, Maralit RM, Kim YS, Oshima T, Miwa H, Pang J, Siah KTH. Impact of the coronavirus disease 2019 pandemic on irritable bowel syndrome. J Gastroenterol Hepatol. 2021 Aug;36(8):21872197. doi: 10.1111/jgh.15466. Epub 2021 Mar 4. PMID: 33615534; PMCID: PMC8014795.

5. Hod K, Melamed S, Dekel R, Maharshak N, Sperber AD. Burnout, but not job strain, is associated with irritable bowel syndrome in working adults. J Psychosom Res. 2020 Jul;134:110121. doi: 10.1016/j.jpsychores.2020.110121. Epub 2020 Apr 20. PMID: 32371342.

6. Sunjaya DK, Herawati DMD, Siregar AYM. Depressive, anxiety, and burnout symptoms on health care personnel at a month after COVID-19 outbreak in Indonesia. BMC Public Health. 2021 Jan 28;21(1):227. doi: 10.1186/s12889-02110299-6. PMID: 33509159; PMCID: PMC7840791. 